\title{
Estimating the Willingness-to-Pay for Road Safety Improvements
}

\author{
LUIS I. RIZZI and JUAN DE DIOS ORTÚZAR \\ Department of Transport Engineering, Pontificia Universidad Católica de Chile, Santiago, Chile
}

(Received 7 April 2005; revised 26 October 2005; accepted 26 December 2005)

\begin{abstract}
The value of road safety is the fundamental input in social cost-benefit analysis of road safety schemes. It is also an increasingly important input in the social evaluation of almost any transport infrastructure project. This value is given by the amount that people are willing to pay for reducing the risk of a becoming a fatal victim or of suffering a serious injury. Traditionally, road safety willingness-to-pay has been estimated by means of contingent valuation and other surveys without making explicit reference to a particular travel demand context. The paper advocates the use of stated choice techniques that allow one to recreate the context of a particular trip customized to the respondent's past experience. For this and other reasons, it is argued that the proposed method is clearly superior to previous methods for estimating people's willingness-to-pay for improved road safety. The paper also provides a summary of the Chilean experience on road safety valuation using stated choice techniques; and it concludes by showing the importance of conducting local studies to elicit people's willingness to pay for safety.
\end{abstract}

\section{Introduction}

Road accidents are one of the worst side-effects of road mobility worldwide; this is especially true in the case of developing countries where 'road systems' are far from mature and many hundreds of thousands of fatalities (and many more seriously injured victims) are experienced unashamedly every year. On the other hand, in more advanced countries road safety has been steadily improving since the 1970s. It seems that an important reason may have been the incorporation of the value of reducing fatal accidents and serious injuries in the social evaluation of projects, an advance that it is still in-the-waiting in second- and third-world countries.

One important conceptual advance in the state of practice was achieved in the 1980s by valuing road safety according to subjective preferences rather than by using the heavily criticized human capital (HC) approach. HC rests on accounting principles: the benefit of avoiding a premature death is given by the present value of the income flow the economy could lose in that case. More appropriately, the 
value of risk reductions (VRR) - initially known as the value of a statistical life-is based on subjective preferences and simply given by the amount of money that individuals are willing to pay for reducing the risk of their premature death while performing a certain risky activity. As turning from HC to VRR obviously yields higher benefits for risk avoidance, the social net benefit of safety policy measures has increased in recent years, prompting many road-safety interventions, otherwise not socially profitable, in the developed world. Unfortunately, in most developing countries the cost-benefit analysis of road safety schemes is quite precarious. ${ }^{1}$ Even in the case of second-world countries such as Chile, with a long tradition of using social cost-benefit analysis for road scheme appraisal, ${ }^{2}$ road safety benefits are not officially added to other benefits such as travel time savings. The safety value is considered, at best, an indicative figure and is based on the HC approach. This way, many potential investments in safer infrastructure do not appear profitable. The impact that the VRR may have on the estimation of the social benefits of road safety schemes will be shown below.

The VRR for road contexts was estimated originally using contingent valuation (CV), standard gamble or the chain method (Viscusi et al., 1991; Jones-Lee et al., 1993; Beattie et al., 1998; Carthy et al., 1998), but the approach, in general, was heavily criticized by specialists in human behaviour (Fischhoff, 1991, 1997) and economics (Hausman, 1993; Diamond and Haussman, 1994). In those original studies, people were confronted with situations expressing risk as tiny probabilities, and needing a trade-off between risk and money to arrive at a monetary value. ${ }^{3}$ This kind of a simulated context may not bear upon actual choices on route selection where individuals have to consider a bundle of attributes describing each alternative (i.e. travel time, toll and safety in a route choice context).

Rizzi and Ortúzar (2003) proposed a different approach based on stated choice (SC) techniques. An SC survey asks individuals to choose among different alternatives, the attribute levels of which vary according to a statistical design aimed at maximizing the precision of the estimates; as such, SC allows the analyst to mimic actual choices with a high degree of realism and for this reason many experts believe that it is an appropriate elicitation method for the valuation of intangibles (McFadden, 1998; Louviere et al., 2000). The approach was also later applied by De Blaeij et al. (2002), Iragüen and Ortúzar (2004) and Hojman et al. (2005).

The aim of the present paper is twofold. First, it wants to contrast the difference between SC and CV techniques and to put forward the arguments that support our claim that SC is a superior elicitation method. Second, it describes the Chilean experience about the application of this method. The paper is structured as follows. The second section discusses the theory of road safety valuation and shows how to elicit the VRR using discrete choice data. The third section explains the differences between a CV and an SC survey, within the context of public works aimed at improving road safety. The fourth section summarizes part of the Chilean experience in the subject and reports the main figures estimated so far. The last section contains conclusions.

\section{Value of Fatal Risk Reductions in a Road Safety Context}

Assume a route is used by $M$ users. If a person travels more than once in a reference period, say $n_{m}$ times, $\mathrm{s} /$ he gives rise to $n_{m}$ pseudo-members totalling a population of $N=M n_{m}$ observations; from now on these will be called the 
individuals of a population. This population exactly amounts to the flow on a route in a given period (say, a year). ${ }^{4} \mathrm{~A}$ route is defined as a path connecting one origin-destination pair. A trip on a route provides a level of dissatisfaction given by a deterministic indirect utility function $V=V(r, c, t)$, where $r$ is the risk of a fatal accident, $c$ is the cost of travel and $t$ is the travel time on a route. Jones-Lee (1994) formally defined the VRR as the value of avoiding one expected death, and this corresponds to the population (or sample) average of the marginal rate of substitution between income and risk of death for person $j\left(\mathrm{MRS}_{j}\right)$ plus a covariance term that accounts for possible correlation between willingness-to-pay (WTP) and reduced risk $\left(\delta r_{j}\right)^{.5}$

$$
\begin{gathered}
\mathrm{MRS}_{j}=\frac{\partial V_{j} / \partial r}{\partial V_{j} / \partial c \mid v=\bar{v}}, \\
\operatorname{VRR}=\frac{1}{N} \sum_{j=1}^{N} \mathrm{MRS}_{j}+N \operatorname{cov}\left(\mathrm{MRS}_{j},\left|\delta r_{j}\right|\right),
\end{gathered}
$$

In empirical work, it is assumed that there is no correlation between WTP and $\delta r$ in the population. Then, equation (2) simplifies to equation (3), and to estimate the VRR it is sufficient to have a good estimate of the MRS. This assumption would be correct, for example, if $\delta r$ were the same for every individual. ${ }^{6}$

$$
\mathrm{VRR}=\frac{1}{N} \sum_{j=1}^{N} \mathrm{MRS}_{j} .
$$

MRS can be interpreted as an implicit value for the own life and averaging it over all individuals travelling on the route yields the VRR. The MRS clearly depends on personal risk perceptions according to the functional form of $V_{j}$. The same analysis can be carried out in terms of fatal crashes, $f$, instead of risks, $r$. However, in this case, VRR is derived differently (but obviously yields the same value):

$$
\mathrm{VRR}=\frac{1}{e} \sum_{j=1}^{N} \frac{\partial V_{j} / \partial f}{\partial V_{j} / \partial c \mid v=\bar{v}}=\frac{1}{e} \sum_{j=1}^{N} \mathrm{SVCR}_{j},
$$

where $e$ is the number of fatalities per crash, and SVCR is the subjective value of fatal crash reductions and is a Lindahl price (Varian, 1992, ch. 23). Equation (4) embodies the definition of community WTP for a public good, road safety in this case, as the sum of individual marginal rates of substitution between income and number of fatalities. If one thinks in terms of a hypothetical tolled route whose operators were able to extract the full consumer's (compensatory) surplus, SVCR would be the maximum toll increase due to a safety improvement for individual $j$, such that $\mathrm{s} /$ he is as well-off as before the improvement. If VRR is higher than the cost of reducing one fatality, the safety project should be desirable from the community standpoint. The rest of this section assumes that $e=1$.

The section will now show one advantage of dealing with the variable number of fatal crashes, rather than risk, in empirical work. From equations (3) and (4), it follows that: 


$$
\mathrm{VRR}=\sum_{j=1}^{N} \mathrm{SVCR}_{j}=\frac{1}{N} \sum_{j=1}^{N} \mathrm{MRS}_{j}+N \operatorname{cov}\left(\mathrm{MRS}_{j},\left|\delta r_{j}\right|\right)
$$

In other words, estimating the SVCR and aggregating across individuals will yield the correct VRR irrespective of $\operatorname{cov}(\bullet, \bullet)$, and this follows from the very definition of our public good: one statistical death reduction ${ }^{7}$ (per unit of time) on a particular route. ${ }^{8}$ This suggests the following type of survey for eliciting VRR: rather than asking people to place a value on risk reductions, they should be asked to value a reduction in fatal crashes, a task the authors believe is far easier from the respondents' standpoint for reasons to be advanced below. ${ }^{9}$

\section{Making the Model Operational ${ }^{10}$}

The model can be made operational within a (binary) choice framework where the indirect deterministic utility of each available alternative is:

$$
V_{i}=\alpha f_{i}+\beta c_{i}+\gamma t_{i}(i=1,2)
$$

where $f$, which is the number of fatal crashes, enters utility in an additive way. As the modeller does not possess all the relevant information, s/he must assume randomness in the utility function. Random utility, $U$, is simply expressed as the sum of two terms: deterministic utility, $V$, and a random component, $\varepsilon$ :

$$
U_{i}=V_{i}+\varepsilon_{i}
$$

and it is assumed that each alternative $i$ has a probability of being chosen given by the probability that $U_{i}$ is the highest random utility. A useful extension of equation (7) is to parameterize indirect utility according to socio-economic (SE) variables (Rizzi and Ortúzar, 2003, provide a microeconomic rationale for it) in order to attain what can be called deterministic taste variations:

$$
V_{i j}=\left(\alpha+\sum_{l} \alpha_{l} s_{l j}\right) f_{i j}+\beta c_{i j}+\lambda t_{i j} \quad(i=1,2)
$$

where the binary variable $s_{l j}$ represents the SE characteristic $l$ of individual $j$, and $i$ the choice alternative. ${ }^{11}$ This is an interesting way of incorporating SE variables, with the advantage that if the information is used to estimate SVCR, say, (8) states that there may be different coefficients for each attribute depending on the characteristics of the individual. If the SE variables are excluded, the SVCR is equal to $\alpha / \beta$ for every individual. Also, note that by computing $\lambda / \beta$, the subjective value of time (SVT) is obtained (Gaudry et al., 1989). One could also add a new variable in equation (6) to account for the impact that severely injured victims may have on deterministic utility. Proceeding analogously as in (4), the VRR for avoiding one severely injured victim could be computed. The rest of the paper will use the simpler utility function (7).

If the random terms distribute identically and independently (iid) Gumbel between alternatives and across individuals, the popular multinomial logit (MNL) model is obtained and the probability of choosing alternative $i$ is given by: 


$$
\operatorname{Prob}(i)=\frac{\exp \left(\lambda V_{i}\right)}{\sum_{m=1,2} \exp \left(\lambda V_{m}\right)}
$$

where $\lambda$ is a scale factor inversely related to the unknown standard deviation of $\varepsilon$, and in practice has to be normalized to one as it is not identifiable (Ortúzar and Willumsen, 2001, ch. 8).

The MNL is not capable of addressing the issue that many responses may be provided by each individual in the SC case. One needs a more powerful model that allows correlation among the choices made by the same person. The mixedlogit model (Train, 2003) allows one not only to do that, but also to consider random parameters (i.e. that $\alpha, \beta$ and $\gamma$ distribute according to a certain distribution in the population). In this case, random taste variations are present implying a potentially more realistic assumption about behaviour, particularly within the context of SC experiments. The mixed logit (ML) choice probabilities consist of a logit kernel that has to be integrated over the distribution of taste parameters:

$$
\operatorname{Prob}(i)=\int \frac{\exp \left(V_{i}\right)}{\sum_{m=1,2} \exp \left(V_{m}\right)} f(\alpha, \beta, \gamma \mid \Xi) \mathrm{d} \alpha \mathrm{d} \beta \mathrm{d} \gamma
$$

where $f(\bullet)$ is the joint distribution of the parameters $\alpha, \beta$ and $\gamma$, and $\Xi$, the (usually unknown) population parameters that characterize the distribution. This model has seen much use recently by researchers, but its adaptation by practitioners still awaits the development of easy-to-use software and a consensus in the way results should be interpreted (Hensher and Greene, 2003; Sillano and Ortúzar, 2005).

\section{Estimating the Value of Risk Reductions in a Road Safety Context: Stated Choice versus Contingent Valuation}

Jones-Lee and Loomes (1995) noted the relevance of estimating the appropriate VRR for a particular safety context. Thus, it is clear that the VRR required for appraising road safety projects must come from people's preferences for improved road safety. In this regard, Jones-Lee et al. $(1985,1993)$ did pioneering work in estimating VRR applicable to road contexts. Their work consisted, basically, of a combination of $\mathrm{CV}$ and risk-risk surveys. The CV component was conducted to estimate a money value for reducing one particular road safety risk, measured in terms of the likely trauma to be suffered after a road crash. As this trade-off (money versus risk) was considered a demanding cognitive burden for the respondent, a risk-risk survey was also applied to chain the marginal rate of substitution among different traumas. Then it was considered easy-to-obtain money values for every risk considered.

In the CV survey, the means to achieve the risk reduction of only one trauma was an unnamed device to be used within the car that could be categorized as a private good. The effectiveness of the device was measured in terms of risk reduction; the values of baseline risk and risk improvements were all real, so people found themselves trading off little amounts of money with risk values the order of magnitude of which were around $10^{-6}$. There are three problems with this type of survey: 
- A device did not have the public good-nature of road safety projects (it resembled the type of service provided by, for instance, air bags); apparently, it was used to avoid problems related to revealing WTP for public goods.

- A more serious shortcoming relates to the way the risk variable was introduced; there is enough evidence about the difficulty that people have in dealing with probabilities, especially as these are of decreasing order of magnitude (O'Brien et al., 1998).

- The most serious problem relates to the survey context that does not appropriately replicate a usual market scenario relevant to the kind of good being valued: conventional $\mathrm{CV}^{12}$ surveys do not place the respondent in the context of a particular road trip. In fact, these surveys are only concerned with tradeoffs between money and risk ignoring other key attributes such as travel time.

In fact, although the first two shortcomings could be solved within the CV framework, the third cannot be dealt with appropriately within a conventional CV survey.

The SC approach proposed by Rizzi and Ortúzar (2003) attempts to address the above three deficiencies. First, the survey is about a route choice for a particular trip that the respondent periodically undertakes. The particular trip is described in enough detail to provide the respondent with a familiar market environment, implicitly providing all the relevant background information required for making a decision. The choice situation includes alternative routes for completing a trip that are characterized by their toll, travel time and accident frequency per year. This context increases the realism of the hypothetical choice scenario, a fundamental condition for accomplishing success in the use of stated preference techniques (McFadden, 1998; Louviere et al., 2000). Hence, the SC approach addresses the most serious shortcoming of CV surveys that are only focused on trading-off money versus risk without considering a particular travel environment. $^{13}$

Two other improvements were introduced by Rizzi and Ortúzar (2003). ${ }^{14}$ First, the difference in danger of each route was conceived in terms of different road safety designs, not in terms of a private device. In the SC survey, road safety has the nature of a public good since the road design affects all car drivers traversing the route. Also, the very nature of route choice helps to eliminate the problem of revealing demand for public goods to a large degree. The respondent has to choose between routes for a particular trip that $\mathrm{s} /$ he has to undertake to accomplish a certain activity at the destination. Thus, it is in his/her best interest to choose the best route to suit his/her travel demand for that particular trip, i.e. to decide among the best combination of toll, travel time and safety. The incentive to free-ride is minimal (or even zero), since the respondent is well aware that the toll is actually the same for every car driver. The incentive to behave altruistically is also low, because if a respondent always chooses the safest route for this reason, s/he would be revealing a low value of time compared with safety; so, if $\mathrm{s} /$ he personally values travel time high when travelling, it would not be in his/ her best interest to choose against faster routes.

The second improvement brought about by Rizzi and Ortúzar (2003) is the treatment of the risk variable itself. The present authors do not believe that laymen consider risk as an objective probability (i.e. as derived by the safety engineer), but as an entity that is the result of complex mental processes where risk perceptions and attitudes play an important role. Most people develop an 
idea about the level of safety of a given route through their personal risk perception, when driving, and through information mostly coming from the media. When there is a road accident, the information on the media is stated in terms of numbers: the number of fatalities, the number of seriously injured victims, etc., and the frequency with which a certain road is involved in crashes helps to get an idea of how dangerous it is. We are not suggesting that people keep mental accounts of the number of crashes on each route they (may) travel; however, we strongly believe that if people care about safety, the idea of 'how safe a route is' is derived from the above facts and not from objective probabilities.

The above argument is in agreement with the concept of a subjective probability in the sense of Anscombe and Aumann (1963). These authors show how rational individuals can derive subjective probabilities for events without thinking in terms of objective probabilities. With this theoretical background, we hold that respondents can combine their personal knowledge of how dangerous a regularly used route is, with objective information related to the number of victims, in order to arrive to a subjective probability of their own likelihood of being involved in a fatal crash.

As analysts, the present authors do not need to know what these subjective probabilities are to proceed with the analysis. From an economic standpoint, equation (4) shows that it is sufficient that people have well-defined preferences in terms of fatal crash reductions to arrive at subjective probabilities. As Bronfman and Cifuentes (2003) found that private motoring is perceived as a well-understood risk, the present authors believe that a road crash is a familiar concept and, thus, it is argued that most people probably have some sort of well-defined preferences about this good (Nash, 1990). ${ }^{15}$ Thus, it was decided to use the number of fatal crashes as a risk-proxy variable.

In an SC study people have to choose from pairs of alternative routes, the risks of which can be only marginally different from the baseline risk (i.e. marginally different from the baseline number of crashes). Special care has to be taken to ensure that the alternative routes in the hypothetical choice scenarios are of a similar nature to the route people had driven through. This way one can be confident that respondents are projecting the sample-selection route baseline risk (whatever their risk conceptions are) onto the routes in the choice pairs. Hence, the modelling results should yield plausible monetary values for small changes in a neighbourhood of the baseline risk level of each route but not at all for major changes in road safety.

A further improvement was considered by Hojman et al. (2005). Within the same SC survey, they considered the risks of becoming a fatality and of becoming a severely injured victim. This way, respondents have to think ex-ante about the two most severe risks they face when driving. This approach is also different to the method used by Jones-Lee and colleagues to value the risk reduction of severely injured victims. In particular, Jones-Lee et al. (1993) place respondents in the hypothetical scenario of having been severely injured as a consequence of a road crash, with it associated health status that could include the chance of dying as a consequence of that particular trauma. Respondents were then offered the possibility of undergoing a certain medical treatment: if this went well, they would recover their before-the-crash health status; but if it went badly, they would die. According to the probabilities assigned to each likely outcome (success or failure of the treatment), people would answer whether or not they would accept the treatment. This type of survey is called a risk-risk survey. 
Although the approach allows the researcher to put a monetary value on a particular trauma, the context of the survey does not correspond to an ex-ante situation in terms of route choice.

\section{Value of Risk Reductions for Chilean Roads}

Values of road safety for Chilean roads have been estimated by Rizzi and Ortúzar (2003), Iragüen and Ortúzar (2004) and Hojman et al. (2005). ${ }^{16}$ This section will briefly describe this empirical research by characterizing the context of the hypothetical market situation and the obtained results.

\section{Context of the Hypothetical Trip}

Since the three surveys were quite similar in spirit, the paper will concentrate on that by Rizzi and Ortúzar (2003). It was conducted in order to elicit drivers' valuations of fatal crash reductions for Route 68, linking the conurbations of Santiago, Chile's capital city, and Valparaíso, the country's largest port and second biggest city; this route is approximately $120 \mathrm{~km}$ long. The survey was administered to a sample of 342 individuals during the southern summer 19992000. Due to budget constraints, it was not a completely random sample. Respondents were recruited among private companies and public organizations with the condition that they must have driven on Route 68 at least once within the year previous to the survey. The questionnaire was printed and handed over to respondents, with a response rate around $40 \%$. The sample's average family income was somewhat higher than the average family income for households with a car in Chile; and it was much higher than the average Chilean family income. It was an expected result since car ownership is positively correlated with family income.

To achieve truly realistic scenarios, after several pilots, pretests and focus group work conducted by a specialized psychologist, it was decided that several contexts should be created. First, there were trips from Santiago to Valparaíso, and vice versa; second, some of the trips were assumed to have taken place on the weekend with the purpose of attending a social meeting; other trips were deemed to occur on a regular working day for reasons of work or personal errands. With respect to trips on working days, the time of day could be either the morning or the evening. In every case, the journey was assumed to be unavoidable; in other words, it had to be done, so there was no room for a non-purchase option (Olsen and Swait, 1998).

The true baseline risk was considered for each of the routes. In each SC experiment people had to choose from pairs of alternative routes, the risks of which could be only marginally different from the baseline risk (i.e. marginally different from the baseline number of crashes). Special care was taken to make respondents aware that the alternative routes available in the hypothetical choices were of a similar nature to the route they had once used, so that respondents could project the sample-selection route baseline risk (whatever their risk conceptions were) onto the routes in the experiment.

The wording of the text introducing respondents to the choice game (i.e. in Spanish in the survey form) for a trip taking place at the end of a regular working day from Valparaíso to Santiago is shown below as an example: 
You must return to Santiago after spending a regular working day in Valparaíso. Your journey has the following characteristics:

- You drive your own car

- You pay for the total cost of the trip, including the toll

- You have to return after 8.00 pm.

- You have to choose between two routes for your return-trip (both are similar to the current Route 68 Santiago-Valparaíso), considering the following three factors: the toll, the travel time en route and the number of fatal crashes on each route. The latter is defined as the number of accidents per year in which at least one person travelling by car dies.

We now ask you to carefully consider the next nine choice situations; in each one of them you are asked to pick up one of the two possible routes for making the trip. Please consider each choice situation independently of the other situations.

With reference to the number of accidents, in 1997 there were 12 crashes in which one of the car occupants died on Route 68.

Thus, the context is clearly defined: day, time of day and trip purpose are all specified; the person who answered the questionnaire was the driver and $\mathrm{s} / \mathrm{he}$ had to pay for the toll. Many motorways operate under a private toll system in Chile and a system of concessionaires is being introduced on a nationwide basis. Thus, people are already familiar with changing toll charges and, besides, the government has informed that a strategy for the future is to increase tolls if the concessionaires manage to achieve certain quality improvements (i.e. safety related). As defined, safety clearly affects the individual well-being related to a particular trip, so there is little room for an altruistic choice. The 'realism' of the choice context was increased to a plausible maximum, reducing the possibility of strategic bias.

To keep consistency between the theoretical model and the hypothetical nature of the survey, respondents had to assume that the baseline risk, from which the risk variable pivots off, is the same in both routes and it is also the same compared with the current situation. As a referee noted, this implies that somehow the flow has doubled. Respondents dealt with this issue without problem, since the wording of the survey was clear in explaining that the hypothetical context with two routes was fictitious; in fact, the two-route scenario was only intended to elicit people's preferences for allocating resources for better road managing. ${ }^{17}$

Table 1 shows an example of the cards defining the choice scenarios. ${ }^{18}$ In each one the pair of routes offered differed in their travel times, toll charges and number of fatal crashes (for details on the experimental design and how the nine choice scenarios were devised, see Rizzi and Ortúzar, 2003).

Table 1. Typical card from the Route 68 Stated Choice game

\begin{tabular}{lcc}
\hline Choice situation number & Route 1 & Route 2 \\
\hline Travel time & $1 \mathrm{~h} 30 \mathrm{~min}$ & $2 \mathrm{~h}$ \\
Fatal crashes & 12 & 20 \\
Toll (US\$) & 8 & 5
\end{tabular}


Two other SC surveys have been conducted recently in Chile using a webpage questionnaire administered through the Internet. Hojman et al. (2005) elicited WTP for reducing both the number of fatalities and of severely injured victims on two interurban roads in Chile: one was Route 68, the other Route 5 between Santiago and Rancagua, $100 \mathrm{~km}$ to the south. The sample size was 495 respondents evenly distributed between both routes. Iragüen and Ortúzar (2004) elicited WTP for reducing the number of fatal victims on urban streets and their survey was answered by 320 respondents. Both SC surveys were similar in nature to that described above, but adapted to their specific road contexts. However, as both surveys were on a webpage, this may have biased upward a little the family income of the respondents.

\section{Survey Results}

All the relevant values were originally estimated in Chilean currency for the corresponding year. These values were adjusted for inflation to January 2005 Chilean pesos (according to the UF index ${ }^{19}$ ) and they were converted to January 2005 US\$ using the average January 2005 exchange rate. ${ }^{20}$ The Chilean peso freely floats with respect to the US\$ and, in the last 5 years, the exchange rate has been very volatile making the adjustment necessary. Readers going to the original papers should bear this in mind.

Several new models were estimated using different indirect utility specifications and different assumptions about the error terms. Attention will be restricted to the mean estimates and 95\% confidence intervals from binary logit models (Table 2). The acronym for the value of fatal risk reduction will be simply VRR and that for the value of a severely injured risk reduction, VSI. In the rest of this section, R\&O will refer to results of the Rizzi and Ortúzar (2003) data; I\&O to results of Iragüen and Ortúzar (2004); and HO\&R to results of Hojman et al. (2005).

Comparing $\mathrm{R} \& \mathrm{O}$ against I\&O shows a sharp decrease in the VRR. This result was expected since urban roads are not only much safer, but also perceived as such. However, the comparison between the VRR for Route 68 between R\&O and HO\&R is somewhat problematic. First, the latter aimed at estimating both the VRR and the VSI, whereas the former only elicited the VRR. Theory suggests that

Table 2. Mean estimates and 95\% confidence intervals from binary logit models (US\$)

\begin{tabular}{|c|c|c|c|c|}
\hline & $\begin{array}{c}\text { Rizzi and } \\
\text { Ortúzar (2003) }\end{array}$ & $\begin{array}{l}\text { Iragüen and } \\
\text { Ortúzar (2004) }\end{array}$ & $\begin{array}{c}\text { Hojman et al. }(2005), \\
\text { Route } 68\end{array}$ & $\begin{array}{l}\text { Hojman et al. } \\
\text { (2005), Route } 5\end{array}$ \\
\hline $\begin{array}{l}\text { Value of risk } \\
\text { reductions } \\
\text { (VRR; death) }\end{array}$ & 773920 & 290382 & 305220 & 301868 \\
\hline $\begin{array}{l}95 \% \text { confidence } \\
\text { interval }^{\text {a }}\end{array}$ & $660779-948861$ & $263370-324147$ & $227133-340677$ & 201 023-398 183 \\
\hline $\begin{array}{l}\text { Value of a severely } \\
\text { injured risk } \\
\text { reduction (VSI; } \\
\text { severe injury) }\end{array}$ & - & - & 124604 & 149637 \\
\hline $\begin{array}{l}95 \% \text { confidence } \\
\text { interval }^{\mathrm{a}}\end{array}$ & - & - & $91638-163653$ & $116192-190278$ \\
\hline
\end{tabular}

${ }^{\mathrm{a} C}$ Confidence intervals were calculated following Armstrong et al. (2001). 
valuing two goods in conjunction will decrease the value of the package compared with the situation in which both goods are valued separately, due to the package effect related to the budget constraint (Saelesminde, 2003). Second, between the time of the R\&O and HO\&R surveys, Route 68 was substantially upgraded and safety improved. These two facts account partly for the sharp fall in the VRR.

An unexpected result is the low VRR for deaths in Route 5, as this is considered one of the most dangerous routes in Chile. In fact, a higher value than those observed for both Route 68 and the urban roads was expected. ${ }^{21}$ To some extent the package effect could be one reason for this since the number of severely injured victims in this route is quite high.

An important point is that the difference between the VRR and the VSI for both Routes 5 and 68 is much smaller than that reported elsewhere. The data imply that avoiding a seriously injured victim is valued around half the value of avoiding a fatal victim in both cases. Jones-Lee et al. (1993), in a landmark study for the UK, estimated the VSI as $9.5 \%$ of the VRR, a figure much smaller than our values. However, the UK figure corresponds to a weighted average of the values for all the potential severities of a non-fatal injury classified as serious in the UK, whereas the Chilean figure is derived from the respondents' own judgement on what constitutes a severe injury. It is then quite difficult to make a genuine comparison between the results of these two studies, if not impossible.

The 95\% confidence intervals given in Table 2 show that in all cases the upper range is between 1.4 and 2.0 times the lower range and the spread of the intervals is within an order of magnitude. This does not suggest great variability within samples. Neither is great variability observed between samples.

It is important to mention that mixed-logit models were also estimated with the data. However, although the model fit was significantly superior (in large part due to the appropriate treatment of the problem of repeated observations in SP data, see Ortúzar et al., 2000) point estimates were obtained that were almost identical to those in Table 2; interestingly, this is not an uncommon result (Brownstone, 2001). However, the confidence intervals tended to be wider and this made the interpretation of the results a little more involved (Hensher and Greene, 2003; Sillano and Ortúzar, 2005). For these reasons, we do not present further results here.

If one turns to compare the results with those of studies undertaken in developed countries (Evans, 1994; Environmental Protection Agency, 1999), the Chilean value of road safety would appear to be strikingly low. However, first, the mean average income (i.e. around US $\$ 2000$ per family/month) in the three Chilean samples is clearly below the average income of car users in most developed countries. Second, the elasticity of utility with respect to income is a relevant value closely related to risk aversion. The authors strongly believe that Chileans are less risk-averse than people from developed countries, and this clearly pushes the VRR downwards. Third, the high VRR obtained in developed countries may be partly due to biases introduced by the extensive use of the $\mathrm{CV}$ technique. Among other deficiencies, CV usually implies a trade-off between probabilities of risk and money in a not completely specified context. Thus, it is not surprising that an unduly high VRR could be obtained. The context in which we set up the choice situations is well defined and easily understood by most people, and real market restrictions are introduced to prevent respondents producing unlikely responses. This has the effect of tempering responses and precluding people to produce 'outliers'. In fact, De Blaeij et al. (2002) reported a similar finding. ${ }^{22}$ 
Finally, the importance of undertaking local studies must be stressed. In their absence, one needs to resort to the transference of values estimated elsewhere. For example, Miller (2000) conducted a meta-analysis based on VRR studies undertaken in many developed countries in order to derive the VRR for any country by transferring values based on a 1995 gross domestic product per-capita adjustment. Adjusting to 2005 values by the US Consumer Price Index, ${ }^{23}$ the work of Miller would allow one to derive values for Chilean road fatalities ranging from US\$747 000 to US\$1 120000 . Although these figures fit relatively well with the values found by R\&O for Route 68 (US\$660 779-948 861), this is by pure chance as the per-capita income of the present sample is much higher than the Chilean 1995 gross domestic product/capita considered by Miller. Furthermore, if one compares Miller's values for Chile with the rest of the values reported in this paper, there is no coincidence at all. In our opinion, a shortcoming in Miller's meta-analysis is not controlling for risk aversion, which is a most difficult task indeed.

If from a cost-benefit analysis standpoint the application of transferred values to the Chilean case would lead to an over-investment in road safety, the practical consequences of applying the VRR rather than the HC value in Chile can be judged by looking at the conclusions of two recent studies on road safety that relied on the R\&O values. Brahm et al. (2002) examined a policy of mandatory daytime running lights in cost-benefit analysis terms; the project considered equipping all new cars and retrofitting old cars with daytime running lights. It was found that the net present value (NPV) of the project was negative using $\mathrm{HC}^{24}$ but turned out to be highly positive if the VRR was used instead. Alcoholado et al. (2003) calculated the NPV of installing a system of lighting alarms in a railway station to the south of Santiago, under different accident reduction scenarios. Again, using HC yielded negative NPV in five scenarios; however, applying the VRR allowed three of these scenarios to yield positive NPV. Unfortunately, the results under the VRR approach were not accepted by the Treasury as evidence of the social worth of schemes.

\section{Conclusions}

The paper reviewed the theory of risk reduction valuation from the individual standpoint. It was argued that the correct concept is the VRR, based on individual WTP for more safety, and showed that a simple binary choice context is enough to elicit the VRR using SC data. It discussed to some extent why the authors believe this approach is superior to the more traditional CV method. The main reason for advocating its use rests on the more realistic market simulation it allows.

New model results for three SC experiences undertaken in Chile were then compared. These gave plausible values and showed the feasibility of conducting this type of study in a developing country. It was shown that the value of road safety in Chile is lower than what would be suggested by transferring values from developed countries adjusting by per-capita income; this could be due to the lower-risk aversion prevailing in less-developed nations. Doubts were also cast about the ratio commonly accepted between the value of reducing one fatality and that of reducing a serious injury, suggesting that the latter could be much higher than the usually accepted $10 \%$ if the serious risk is more accurately defined. Finally, the paper also illustrated the applicability of the results in cost-benefit analysis. During the late 1970s and early 1980s, many industrialized countries 
moved from the HC to the VRR in the social cost-benefit appraisal of road schemes, with a clear impact in terms of the reduction in the number of fatal crashes; it is clear from our limited experience here that such a move would contribute to devoting more resources to road safety in developing countries and thus also reduce the unacceptable number of road fatalities currently experienced.

\section{Acknowledgements}

The authors acknowledge the financial support of the Chilean Fund for Scientific and Technological Research (FONDECYT) given to this research through several projects, in particular Project No. 1050672.

\section{Notes}

1. The exception could be a safety scheme funded by The World Bank, where some sort of cost-benefit analysis is usually required.

2. Probably a unique experience within the context of developing countries; even more, the social cost-benefit analysis applied in the case of urban transport schemes ranks among the best worldwide.

3. Some of these studies posed a risk-risk trade-off. However, to arrive at a monetary value, a risk-money trade-off is necessary sooner or later.

4. Actually, a population is a stock variable, whereas a flow is not.

5. $\operatorname{cov}\left(M R S_{j}, \delta r_{j}\right)=\sum_{j} \frac{M R S_{j} \delta r_{j}}{N}-\sum_{j} \frac{M R S_{j}}{N} \sum_{j} \frac{\delta r_{j}}{N}$.

6. To the authors' knowledge, the assumption of zero $\operatorname{cov}(\bullet, \bullet)$ is more a belief than a proven fact.

7. A statistical death reduction means saving one life, on average, per unit of time (whose life is saved is unknown).

8. A referee suggested incorporating $\delta r$ as a design variable. However, the problem lies in how to control for the way the individual perceives his/her own risk reduction. Although one can ask different individuals to value different reductions in the number of road accidents, they still process risk probabilities in a way that cannot be controlled for.

9. One referee noted that the two approaches are mutually consistent only when the respondent, when evaluating the number of crashes, has the correct aggregate flow in mind (i.e. s/he would value an extra fatal crash per year differently if s/he were to make the only trip on that road that year, than when millions of trips would be made on that road). In this sense, although a formulation in terms of number of crashes may sound more natural and easy to understand than a formulation in terms of probabilities to most respondents, the cognitive burden may not become any lighter. Unfortunately, whether the yearly flow indeed affects the valuation of an additional crash cannot be tested with the data available for this paper.

10. This section does not discuss how to estimate VRR by means of $C V$ within a road transport context. There is a considerably literature on the issue and readers are referred to the references to Jones-Lee cited in this paper.

11. All level-of-service parameters can be tested for systematic variations in this form.

12. By conventional CV survey, we refer to most CV surveys undertaken to elicit WTP for road safety in the 1980s and 1990s. These include, mainly, the pioneering work of Jones-Lee et al. and all the surveys described by Schwab and Soguel (1995).

13. The shortcomings of stated preference techniques will not be addressed, since they are common to both CV and SC.

14. These could also be introduced within the CV approach.

15. This may lead someone to think that there could be an inconsistency in (4). As it is a sum of WTP, the more people travel on the route, the higher the WTP for reducing one fatal crash. However, if one is to be consistent with the model in mind, as the number of individuals travelling a route increases, the individual subjective risk reduction brought about by averting one fatal death should decrease. If safety is thought of as any other good in the economy, its value should be related to both the initial level of safety and the magnitude of the safety improvement. Thus, if the magnitude of the improvement diminishes, so does the WTP for it. Depending on this magnitude 
and the initial level of risk, the value of (4) could be higher or less for a route used by a higher flow and the apparent inconsistency is solved.

16. One of the pilot surveys conducted by Rizzi et al. (1999) gave rise to a paper by Jara-Díaz et al. (2000). We will not comment on this work since the quality of the data used by Rizzi and Ortúzar (2003) was clearly superior.

17. The referee also noted that the effect of route choices on road safety was ignored.

18. The relevant flow figure for this table was almost 4 million light-vehicles per year. In a experiment that followed the work described here (Hojman et al., 2005), the vehicle flows were also included in the survey to provide respondents with more information.

19. The UF (Unidad de Fomento) index is elaborated by the Chilean Central Bank and is used for indexation (http://www.bcentral.cl).

20. The exchange rate is also available at the Central Bank site.

21. These findings seem to be at odds with a previous pilot study conducted by Galilea et al. (2000) where a much higher VRR was elicited for Route 5 (mean estimate around US\$1.5 million and confidence interval from US\$0.9 million to US\$3.4 million). However, the sample size of this pilot study was much smaller with only 90 respondents. Notwithstanding, the superior quality of the survey by Hojman et al. (2005) is out of the question.

22. They state, among other reasons: (1) the public good nature of the risk under analysis, and (2) the definition of the payment vehicle. However, they do not give any explanation about whether the survey instrument could affect the outcome of the experiment.

23. The adjustment was made with the inflation calculator at http://www.westegg.com/inflation.

24. Around US\$35 000 only at current prices (CITRA, 1996).

\section{References}

Alcoholado, G., Castro, M., Loewe, I. and Lopez, S. (2003) Plan de Reducción de Accidentes en Cruces Ferroviarios a Nivel. Mimeo (Santiago: Department of Transport Engineering, Pontificia Universidad Católica de Chile).

Anscombe, F. and Aumann, R. (1963) A definition of subjective probability, Annals of Mathematical Statistics, 34, pp. 199-205.

Armstrong, P., Garrido, R. A. and Ortúzar, J. de D. (2001) Confidence intervals to bound the value of time, Transportation Research, 37E, pp. 143-161.

Beattie, J., Covey, J., Dolan, P., Hopkins, L., Jones-Lee, M., Loomes, G., Pidgeon, N., Robinson, A. and Spencer, A. (1998) On the contingent valuation of safety and the safety of contingent valuation: Part 1 -Caveat investigator, Journal of Risk and Uncertainty, 17, pp. 5-25.

Brahm, J., Caussade, S., Correía, R. and Leopold, J. (2002) Implementación de Medidas de Seguridad Vial. Mimeo (Santiago: Department of Transport Engineering, Pontificia Universidad Católica de Chile).

Bronfman, N. and Cifuentes, L. (2003) Risk perception in a developing country: the case of Chile, Risk Analysis, 6, pp. 1309-1323.

Brownstone, D. (2001) Discrete choice modelling for transportation, in: D. Hensher (Ed.) Travel Behaviour Research: The Leading Edge, pp. 97-124 (Amsterdam: Pergamon).

Carthy, T., Chilton, S., Covey, J., Hopkins, L., Jones-Lee, M., Loomes, G., Pidgeon, N. and Spencer, A. (1998) On the contingent valuation of safety and the safety of contingent valuation: Part 2-The CV/ SG 'chained' approach, Journal of Risk and Uncertainty, 17, pp. 187-214.

CITRA (1996) Investigación Diseño de Programa de Seguridad Vial Nacional. Final Report to the Ministry of Public Works (Santiago: CITRA).

De Blaeij, A. T., Rietveld, P., Verhoef, E. T. and Nijkamp, P. (2002) The valuation of a statistical life in road safety: a stated preference approach, in: Proceedings of the 30th European Transport Forum (London: PTRC).

Diamond, P. and Hausman, J. A. (1994) Contingent valuation: is some number better than no number?, Journal of Economic Perspectives, 8, pp. 45-64.

Environmental Protection Agency (1999) The Benefits and Costs of the Clean Air Act, 1990 to 2010 (Washington, DC: US EPA). Available at: http://www.epa.gov/oar/sect812

Evans, A. W. (1994) Evaluating public transport and road safety measures, Accident Analysis and Prevention, 26, pp. 411-428.

Fischhoff, B. (1991) Value elicitation: is there anything in there?, American Psychologist, 46, pp. 835-847.

Fischhoff, B. (1997) What do psychologists want? Contingent valuation as a special case of asking questions, in: R. J. Kopp, W. W. Pommerehne and N. Schwarz (Eds) Determining the Value of Nonmarketed Goods, pp. 189-217 (New York, NY: Plenum). 
Galilea, P., Norambuena, I., Dueñas, F. and Ortúzar, J. de D. (2000) Validación externa del diseño experimental de PD para accidentes fatales interurbanos. Documento de Trabajo No. 81 (Santiago: Department of Transport Engineering, Pontificia Universidad Católica de Chile).

Gaudry, M. J. I., Jara-Díaz, S. R. and Ortúzar, J. de D (1989) Value of time sensitivity to model specification, Transportation Research, 23B, pp. 151-158.

Hausman, J. A. (Ed.) (1993) Contingent Valuation: A Critical Assessment (Amsterdam: North-Holland).

Hensher, D. A. and Greene, W. H. (2003) Mixed logit models: the state of practice, Transportation, 30, pp. 133-176.

Hojman, P., Ortúzar, J. de D. and Rizzi, L. I. (2005) On the joint valuation of averting fatal victims and severe injuries in highway accidents, Journal of Safety Research, 36, pp. 377-386.

Iragüen, P. and Ortúzar, J. de D. (2004) Willingness-to-pay for reducing fatal accident risk in urban areas: an internet-based web page stated preference survey, Accident Analysis and Prevention, 36, pp. 513-524.

Jara-Díaz, S. R., Galvez, T. and Vergara, C. (2000) Social valuation of road accident reductions, Journal of Transport Economics and Policy, 34, pp. 215-232.

Jones-Lee, M. (1994) Safety and the savings of life, in: R. Layard and S. Glaister (Eds) Cost-Benefit Analysis, pp. 290-318 (Cambridge: Cambridge University Press).

Jones-Lee, M. and Loomes, G. (1995) Scale and context effects en the valuation of transport safety, Journal of Risk and Uncertainty, 11, pp. 183-203.

Jones-Lee, M., Hammerton, M. and Philips, P. (1985). The value of safety: results of a national sample survey, Economic Journal, 95, pp. 49-72.

Jones-Lee, M., O'Reilly, D. and Philips, P. (1993) The Value of Preventing Non-fatal Road Injuries: Findings of a Willingness-to-Pay National Sample Survey. Working Paper No. WPSRC2 (Crowthorne: Transport Research Laboratory).

Louviere, J. J., Hensher, D. A. and Swait, J. D. (2000) Stated Choice Methods: Analysis and Application (Cambridge: Cambridge University Press).

McFadden, D. (1998) Measuring willingness-to-pay for transportation improvements, in: T. Gärling, T. Laitila and K. Westin (Eds) Theoretical Foundations of Travel Choice Modelling, pp. 339-364 (Amsterdam: Elsevier).

Miller, T. (2000) Variations between countries in values of statistical life, Journal of Transport Economics and Policy, 34, pp. 169-188.

Nash, C. A. (1990) Appraising the Environmental Effects of Road Schemes. Working Paper (Leeds: Institute for Transport Studies, University of Leeds).

O’Brien, B., Goeree, R., Gafni, A., Torrance, G., Pauly, M., Erder, H., Rusthoven, J., Weeks, J., Cahill, M. and LaMont, B. (1998) Assessing the value of a new pharmaceutical: a feasibility study of contingent valuation in managed care, Medical Care, 36, pp. 370-384.

Olsen, G. D. and Swait, J. D. (1998) Nothing is Important. Working Paper (Calgary: Faculty of Management, University of Calgary).

Ortúzar, J. de D., Roncagliolo, D. A. and Velarde, U. C. (2000) Interactions and independence in stated preference modelling, in: J. de D. Ortúzar (Ed.) Stated Preference Modelling Techniques, pp. 155-172 (London: Perspectives 4, PTRC).

Ortúzar, J. de D. and Willumsen, L. G. (2001) Modelling Transport, 3rd edn (Chichester: Wiley).

Rizzi, L. I. and Ortúzar, J. de D. (2003) Stated preference in the valuation of interurban road safety. Accident Analysis and Prevention 35, 9-22.

Rizzi, L. I., Garrido, R. A., Ivelic, A. M. and Ortúzar, J. de D. (1999) Valor social de la seguridad en carreteras: un enfoque basado en el comportamiento. Documento de Trabajo No. 69 (Santiago: Department of Transport Engineering, Pontificia Universidad Católica de Chile).

Saelesminde, K. (2003) Embedding effects in valuation of non-market goods, Transport Policy, 10, pp. 59-72.

Schwab, C. N. and Soguel, N. (Eds) (1995) Contingent Valuation, Transport Safety and the Value of Life (London: Kluwer).

Sillano, M. and Ortúzar, J. de D. (2005) Willingness-to-pay estimation with mixed logit models: some new evidence, Environment and Planning, 37A, pp. 525-550.

Train, K (2003) Discrete Choice Methods with Simulation (Cambridge: Cambridge University Press).

Varian, H. (1992) Microeconomic Analysis (New York, NY: W. W. Norton).

Viscusi, W. K., Magat, W. A. and Hube, J. (1991) Pricing environmental health risks: surveys assessments of risk-risk and risk-dollar trade offs for chronic bronchitis, Journal of Environmental Economics and Management, 21, pp. 32-51. 
